\title{
A typical presentation of penile fracture
}

\begin{abstract}
Background: Fracture penis is an uncommon injury presenting to the emergency department (ED). Underreporting of this condition occurs due to personal embarrassment. Patients often delay in seeking medical attention; they may withhold the condition for a significant amount of time. ED physicians need to be aware of the social inhibitions and the need for early diagnosis and prompt treatment. A delay in treatment increases the risk of complications such as ischemia, necrosis and penile deformity. Fracture penis is caused by rupture of the tunica albuginea of one or both corpora cavernosa by a blunt trauma to the erect penis. Diagnosis is usually clinical as evident by the characteristic history and clinical presentation. Diagnostic imaging modalities aid in the management of the fracture and associated injuries if present. Nevertheless, prompt recognition and initiation of treatment can significantly reduce the chances of post-injury complications.
\end{abstract}

Findings: We present a case of penile fracture in a young male who came to the hospital after hearing popping sound followed by sudden detumescence while having intercourse along with urethral bleeding, with no swelling or deformity of penis.

Conclusion: Our case report is an attempt to raise the suspicion of fracture penis in case of typical history; even without physical findings that necessitates an immediate surgical exploration.

Keywords: tunica albuginea, corpus cavernosa, penile shaft, penile fracture
Volume 8 Issue 2 - 2020

\author{
Kareem MTaha \\ Department of Urology, Zagazig University, Egypt
}

Correspondence: Kareem M Taha, Kareem MTaha, Department of Urology, Consultant Urologist Zagazig University, Egypt, Tel +20 I 220565349 , Email K_M_T83@yahoo.com

Received: March 04, 2020 | Published: March 3I, 2020

\section{Introduction}

Fracture penis is an uncommon injury. Physicians should be aware of the urgency in the diagnosis and in the initiation of the treatment as any delay increases the risk of complications. Due to the embarrassment associated with such injuries the patients may hesitate to disclose their complaint and getting delayedin seeking medical treatment. Classically the history is starting with a sudden snap, pain, detumescence and a hematoma of the penis with deformity which was not present in our reported case. Recently, the possibility of an early diagnosis based on clinical findings has been emphasized, without relying on specialized imaging studies. $\left.\right|^{t-3}$ It is a disruption of the tunica albuginea of one or both corpus cavernosum due to blunt trauma to the erect penis. ${ }^{2}$ It can be accompanied by partial or complete urethral rupture or by injury of the dorsal nerve and vessels. ${ }^{4}$

\section{Case report}

A 38 years old male patient presented to the hospital after hearing popping sound followed by asudden detumescence while having intercourse along with a profuse urethral bleeding, with no swelling or deformity of penis as shown in Figures $1 \& 2$. Local penile examination was unremarkable therefore, it was a bit misleading. Urethral catheter was inserted gently and carefully which drained clear urine andurethral injury was suspected. Patient was resuscitated and started on broad spectrum antibiotics as per the hospital's protocol subsequently the patient had a considerableperiurethral bleeding that raised the suspicion of an additional underlying pathology; beyond the urethral injury. Ascending andmicturatingcystourethrogramin Figure 3 confirmed the presence of a tear in the tunica albuginea extending to the urethral lumen and draining the blood from the corpora cavernosa directly into the urethra, it did also show a normal filling of the anterior urethra with irregular extraurethral extravasation and finally a penile duplex ultrasound scan in Figure 4 confirmed the presence of multiple subtunical and bilateral extracorporeal small organized hematoma. Although the physical findings were not suggestive of a penile fracture, exploration was offered and advised to the patient in the view of the finding but unfortunately the patient refused to undergo exploration after settling of the urethral bleeding and he was fully and formally informed about the possibility of the associated risks mainly erectile dysfunction. The patient was self-discharged and represented 3 month later, with moderate degree of erectile dysfunction and examination revealed a $3 \mathrm{~cm}$ fibrotic plaque on ventral aspect of left corporeal body.
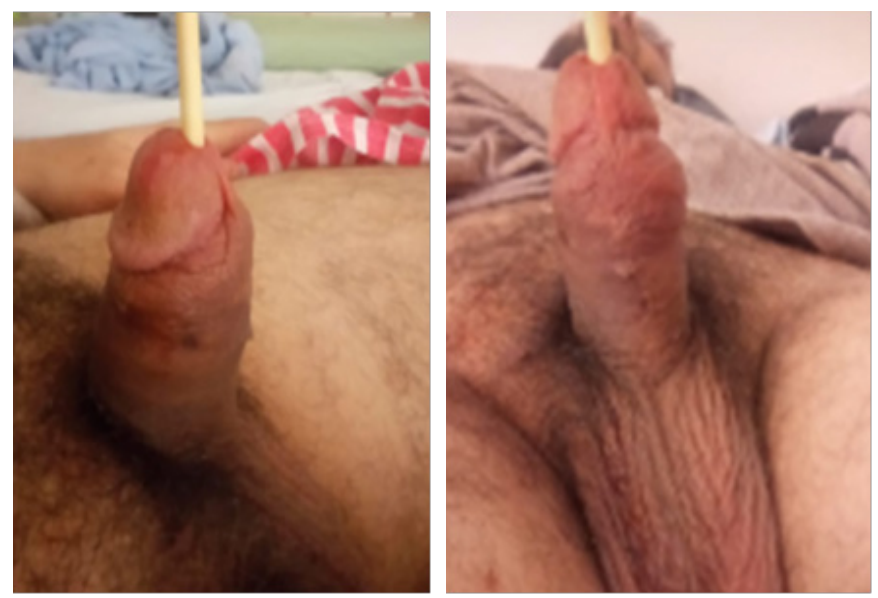

Figures I \&2 Showing nearly normal penile shaft. 


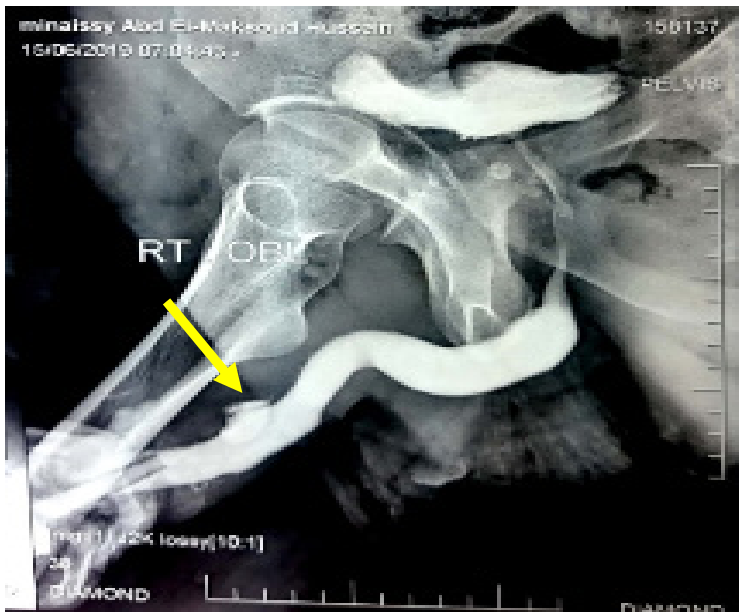

Figure 3 Showing normal filling of ant urethra with irregular extraurethral extravasation (yellow arrow).

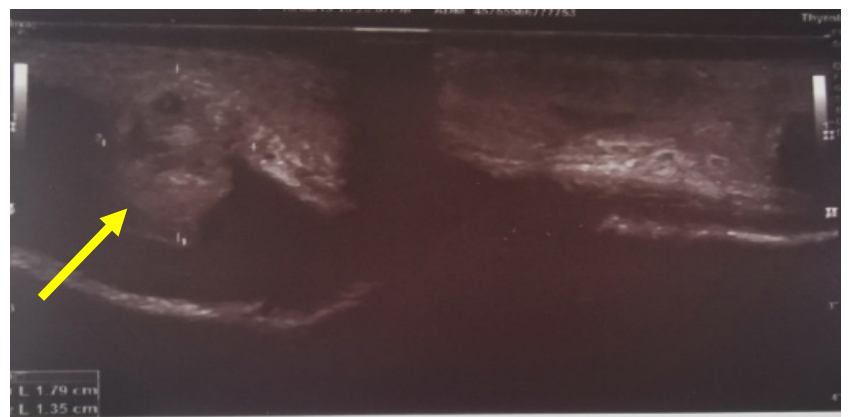

Figure 4 Duplex US showing presence of extracorporeal small organized hematoma (yellow arrow).

\section{Discussion}

Fracture penis, is the rupture of the tunica albuginea of the corpus cavernosa. The rupture occurs when the penis is erectedas the tissue of the tunica albuginea is getting thinner and vulnerable to the sudden increase in the intracorporeal pressure..$^{5-7}$ The incidence is increasing however, it may still be under-reported due to associated guilt and embarrassment. The etiology varies, with penile manipulation during masturbation and 'taghaandan' (in Kurdish meaning to click or snap), whereas vigorous sexual intercourse is still the most common cause ${ }^{8,9}$ Penile fracture is readily diagnosed by a thorough history and physical examination. A history of vigorous sexual intercourse or penile bending during masturbation together with a snapping sound, rapid detumescence and penile discoloration is characteristic in such cases. Examination usually reveals swollen, ecchymotic, tender and deviated penis. Sometimes, the tunical defect can be palpable. Conservative treatment may result in complications in up to $29 \%$ of cases. These include erectile dysfunction, penile curvature, abscess development or debilitating plaques and significantly longer period of hospitalization and recovery. ${ }^{10-12}$ Ultrasonography may corroborate the clinical findings. High frequency probes easily pick up tunica albuginea defects and hematomas. Cavernosography and MRI may be done when the clinical diagnosis cannot be reached, but not at the cost of surgical delay. Retrograde urethrogram and flexible cystoscopy may help in cases with suspected urethral injuries. ${ }^{13-16}$

Any penile injury should be treated as an "emergency until proven otherwise". Though the condition is not that common, it should be managed adeptly to avoid complications such as penile deformity, erectile dysfunction or painful intercourse. ${ }^{17}$ Urgent surgical repair includes procedures such as "evacuation of hematoma, ligation of bleeding vessels, debridement, suturing of tears in tunica albuginea, urethral stenting, and/or end-to-end urethral anastomosis..$^{18}$ Immediate surgical reconstruction usually results in a faster recovery, decreased morbidity, lower complication rates, and lower incidence of long term penile curvature. ${ }^{19}$ Since the repair reduces the complication of fracture it is now the gold standard for treatment of penile fractures. ${ }^{20}$ In our case report, although the physical findings were not suggestive of a penile fracture, exploration was strongly advised in the view of the typical history but unfortunately, the patient refused to undergo exploration and so, developed the mentioned complication.

\section{Conclusion}

Despite that the history and the clinical examination remain the mainstay tools to diagnose the penile fracture still; a low threshold for the exploration is still strongly indicated even in the absence of the typical clinical examination evidences. In conclusion; surgical exploration may have saved many patients from developing nasty associated complications.

\section{Acknowledgments}

None.

\section{Conflicts of interest}

The author declares there is no conflict of interest.

\section{Funding}

None.

\section{References}

1. Restrepo JA, Estrada CG, García HA. Clinical experience in the management of penile fractures at Hospital Universitario del Valle. Arch EspUrol. 2010;63:291-295.

2. Rosenstein D, McAninch JW. Urologic emergencies. Med Clin North Am. 2004;88(2):495-518.

3. Nomura JT, Sierzenski PR. Ultrasound diagnosis of penile fracture. $J$ Emerg Med. 2010;38:362-365.

4. Haas CA, Brown SL, Spirnak JP. Penile fracture and testicular rupture. World J Urol. 1999;17(2):101-106.

5. Meares EM. Traumatic rupture of the corpus cavernosum. J Urol. 1971;105:407-408.

6. Shaeer O. Methylene blue-guided repair of fractured penis. J Sex Med. 2006;3(2):349-354.

7. Gamal WM, Osman MM, Hammady A, et al. Penile fracture: longterm results of surgical and conservative management. J Trauma. 2011;71(2):491-493.

8. Kamdar C, Mooppan UM, Kim H, et al. Penile fracture: Preoperative evaluation and surgical technique for optimal patient outcome. BJU Int. 2008;102(11):1640-1644.

9. Zargooshi J. Penile fracture in Kermanshah, Iran: The long-term results of surgical treatment. BJU Int. 2002;89(9):890-894.

10. Morey AF, Rozanski TA, Wein AJ. Genital and lower urinary tract trauma. Wein: Campbell Walsh Urology. $9^{\text {th }}$ edn. Ch. 83. Philadelphia, Pa: Saunders Elsevier. 2007. 
11. Nicolaisen GS, Melamud A, Williams RD, et al. Rupture of the corpus cavernosum: Surgical management. J Urol. 1983;130(5):917-919.

12. Penson DF, Seftel AD, Krane RJ, et al. The hemodynamic pathophysiology of impotence following blunt trauma to the erect penis. $J$ Urol. 1992;148(4):1171-1180.

13. Kamdar C, Mooppan UM, Kim H, Gulmi FA. Penile fracture: Preoperative evaluation and surgical technique for optimal patient outcome. BJU Int 2008;102(11):1640-1644.

14. Pandyan GV, Zaharani AB, Al Rashid M. Fracture penis: An analysis of 26 cases. Scientific World Journal. 2006;6:2327-2333.

15. Bello JO. Synergism of clinical evaluation and penile sonographic imaging in diagnosis of penile fracture: A case report. J Med Case Rep. 2012;6:321.
16. Ash A, Miller J, Preston D. Point of care ultrasound used to exclude penile fracture. Crit Ultrasound J. 2012;4:17.

17. Dubin J, Davis JE. Penile emergencies. Emerg Med Clin North Am. 2011;29:485-499.

18. Gamal WM, Osman MM, Hammady A, et al. Penile fracture: longterm results of surgical and conservative management. J Trauma. 2011;71(2):491-493.

19. Eke N. Fracture of the penis. Br J Surg. 2002;89:555-565.

20. Rosenstein D, McAninch JW. Urologic emergencies. Med Clin North Am. 2004;88(2):495-518 